(A) Check for updates

Cite this: Food Funct., 2019, 10, 7697

\title{
Araucaria angustifolia (Bertol.) Kuntze extract as a source of phenolic compounds in TPS/PBAT active films
}

\author{
Tamires Barlati Vieira da Silva, (D) a Thaysa Fernandes Moya Moreira, ${ }^{a}$ \\ Anielle de Oliveira, ${ }^{a}$ Ana Paula Bilck, ${ }^{b}$ Odinei Hess Gonçalves, (D) a,c,d \\ Isabel C. F. R. Ferreira, (iD *c Lillian Barros, (iD c Maria-Filomena Barreiro, ${ }^{\text {c,d }}$ \\ Fabio Yamashita, ${ }^{\text {b Marianne Ayumi Shirai }}{ }^{\mathrm{e}}$ and Fernanda Vitória Leimann (D) *a,c,d
}

\begin{abstract}
There is growing interest in the development of biodegradable packaging materials containing natural antioxidant extracts. In this sense, the use of extracts obtained from agro-industrial byproducts has proved to be a sustainable alternative. In this study, Pinhão extract, a byproduct of Pinhão (Araucaria angustifolia (Bertol.) Kuntze) seed consumption, was characterized by HPLC-DAD-ESI/MSn, demonstrating the presence of eight phenolic compounds, (+)-catechin and (-)-epicatechin being the most abundant molecules. TPS/PBAT films containing Pinhão extract were produced by blown extrusion and their properties (tensile properties, thermal characteristics and microstructure) were evaluated in order to determine the effect of the presence of extracts. Results suggested that the interaction between the phenolic compounds of the extract and the polymeric matrix caused the reduction in the crystallinity degree, and an increase in the starch glass transition temperature. The presence of Araucaria angustifolia (Bertol.) Kuntze extract significantly $(p<0.05)$ affected the color and opacity of the film. Regarding water vapor permeation, no significant difference $(p>0.05)$ was detected. However, the water solubility and the contact angle with water (polar solvent) and diiodomethane (non-polar solvent) significantly changed due to the extract addition. Moreover, the Pinhão extract conferred significant antioxidant capacity to the TPS/PBAT films as determined by DPPH, suggesting that this material can be applied as an active packaging material.
\end{abstract}

Received 19th June 2019 Accepted 17th October 2019

DOI: 10.1039/c9fo01315f

rsc.li/food-function ing source of antioxidants is the byproduct generated during the preparation of Pinhão (Araucaria angustifolia (Bertol.) Kuntze) seeds, the sole native gymnosperm of the Atlantic forest in Brazil with great economic, cultural and social importance. ${ }^{2}$ Water used in the cooking process for consumption is turned into an extract rich in phenolic compounds, such as catechin, ${ }^{3,4}$ making this byproduct a promising source of antioxidants to prepare active food packaging materials. De Freitas et $a l .^{3}$ have prepared an active packaging material based on zein added with the cooking water of Araucaria angustifolia (Bertol.) Kuntze seeds using the casting technique and found that the extract was able to enhance mechanical properties (tensile strength and elongation at break) and confer antioxidant capacity.

Santos et $a l^{5}$ studied the extraction of Pinhão seed coats using ethanol : water in different proportions and found that flavonoids accounted for $89-92 \%$ of the phenolic composition, and the B-type (epi)catechin dimer and (+)-catechin were the most abundant compounds. Phenolic acids were present in $7-9 \%$ of the phenolic composition, protocatechuic acid being the predominant molecule. Among the pharmaceutical pro- 
perties of Araucaria angustifolia (Bertol.) Kuntze extracts might be cited the inhibition of salivary $\alpha$-amylase, ${ }^{6}$ and pancreatic lypase, ${ }^{7}$ and also a selective capacity to inhibit the proliferation of human larynx HEp-2 cancer cells. ${ }^{8}$ More recently, Branco et al. ${ }^{9}$ examined the effects of Araucaria angustifolia extract on rotenone-induced mitochondrial complex I dysfunction in human dopaminergic SH-SY5Y cells and concluded that the extract restored complex I assembly and activity. All these findings demonstrate the high potential of Araucaria angustifolia application as a source of bioactive compounds.

Petroleum-based food packaging materials are well known and established materials, and are nearly omnipresent in our daily lives. However, their increased importance and use in the food industry raised questions on the environmental impacts they may cause. ${ }^{10}$ There is, currently, intensive effort from researchers worldwide to investigate alternative applications, namely materials based on polymers extracted from animal and botanical sources such as proteins, carbohydrates, gums, etc. ${ }^{11}$ Among them, starch presents advantages over most common bio-based polymers due to its low cost and high availability. ${ }^{12}$ Starch can be processed by extrusion in the presence of plasticizers and at high temperatures with the same equipment used for synthetic polymers. ${ }^{13}$ However, thermoplastic starch (TPS) presents high hydrophilicity, which leads to limitations in food packaging applications. One alternative to this problem is to blend TPS with other polymeric materials with lower hydrophilicity. ${ }^{14}$

Poly(butylene adipate-co-terephthalate) (PBAT), an aromatic-aliphatic copolyester, is a biodegradable polymer derived from petrochemical resources and presents processing conditions and mechanical properties similar to those of polyethylene. ${ }^{15}$ Many studies were developed focusing on TPS/ PBAT blends, ${ }^{16-20}$ since PBAT is a promising material used to produce environmentally friendly biodegradable materials, while TPS can reduce the cost and increase biodegradability. ${ }^{15}$ Nevertheless, TPS/PBAT offers limitations to blending due to their poor interfacial adhesion. Compatibilizers can be used to overcome this problem. Examples include citric acid, which presents a polar group $(\mathrm{COOH})$ in its chemical structure and is reactive towards starch hydroxyl groups, decreasing starch hydrophilicity and increasing the compatibility with PBAT. ${ }^{21}$

In this work, the effect of adding Araucaria angustifolia (Bertol.) Kuntze cooking water extract to TPS/PBAT films on physical and antioxidant properties was evaluated. The active packaging materials were produced by the reactive extrusion of TPS/PBAT using citric acid as a compatibilizer. The obtained films were characterized regarding their mechanical, thermal, hydrophilic-hydrophobic and microstructural properties, as well as their antioxidant capacity.

\section{Materials and methods}

\subsection{Materials}

Araucaria angustifolia (Bertol.) Kuntze seeds were obtained in a local market in 2017 (Campo Mourão, Brazil). Films were pro- duced from native cassava starch obtained from Indemil (Brazil), PBAT (poly(butylene adipate-co-terephthalate)) supplied by BASF (Ecoflex®, Ludwigshafen, Germany), glycerol (Dinâmica, Brazil) as a plasticizer, and citric acid as a plasticizer/compatibilizer (Vetec, Brazil). For antioxidant determination, the following reagents were used: catechin (standard from Sigma Aldrich), Folin-Ciocalteu reagent (Alphatec), sodium carbonate (Vetec), absolute ethyl alcohol PA (Neon), anhydrous calcium chloride (Alphatec), and DPPH (1,1-diphenyl-2-picryl hydrazine, Sigma Aldrich). Sodium carbonate and ethanol (Vetec Química, Brazil) were of analytical grade. Acetonitrile (Fisher Scientific, HPLC grade) was used in the chromatographic analyses and formic acid was purchased from Panreac Química SLU. The phenolic standards were purchased from Extrasynthèse and water was treated in a Milli-Q water purification system (TGI Pure Water Systems, USA).

\subsection{Araucaria angustifolia (Bertol.) Kuntze seed extract preparation and characterization}

The extract preparation was carried out as described by De Freitas et al. $^{3}$ Briefly, Araucaria angustifolia (Bertol.) Kuntze seeds were cooked in boiling water $\left(500 \mathrm{~g} \mathrm{~L}^{-1}\right)$ for $2 \mathrm{~h}$. Subsequently, the cooking water was separated from the seeds and lyophilized (Liotop L101, Liobrás, Brazil) to obtain a dry extract.

The phenolic profile of Araucaria angustifolia (Bertol.) Kuntze $\left(10 \mathrm{mg} \mathrm{mL}{ }^{-1}\right.$ in water $)$ was determined by HPLC-DAD-ESI/MSn (Dionex Ultimate 3000 UPLC, Thermo Scientific, San Jose, CA, USA). These compounds were separated and identified as previously described by Bessada et al. ${ }^{22}$ Separation was achieved using a Waters Spherisorb S3 ODS-2 C18 ( $3 \mu \mathrm{m}, 4.6 \times 150 \mathrm{~mm}$, Waters, Milford, MA, USA $)$ column thermostatted at $35{ }^{\circ} \mathrm{C}$, using a gradient solvent system with (A) $0.1 \%$ formic acid in water and (B) acetonitrile, as follows: $15 \%$ B (0-5 min), $15 \%$ B to $20 \%$ B (5-10 $\mathrm{min}), 20-25 \%$ B (10-20 min), $25-35 \%$ B (20-30 min), $35-50 \%$ B (30-40 min), subsequent column re-equilibration with a flow rate of $0.5 \mathrm{~mL}$ $\min ^{-1}$. Detection was performed using a DAD $(280,330$ and $370 \mathrm{~nm}$ as preferred wavelengths) and a mass spectrometer (MS). MS detection with electrospray ionization was performed in negative mode (Linear Ion Trap LTQ XL, Thermo Finnigan, San Jose, CA, USA) under the mentioned conditions: sheath gas $\left(\mathrm{N}_{2}, 50 \mathrm{psi}\right)$; source temperature $325^{\circ} \mathrm{C}$; spray voltage $5 \mathrm{kV}$; capillary voltage $-20 \mathrm{~V}$; tube lens offset voltage $-66 \mathrm{~V}$; collision energy 35 arbitrary units. The full scan data were collected from $\mathrm{m} / \mathrm{z} 100$ to 1500 . An Xcalibur ${ }^{\circledR}$ data system (Thermo Finnigan, San Jose, CA, USA) was used for data acquisition.

The identification of phenolic compounds was achieved by comparing retention times, and UV-Vis and mass spectra with those of available standard compounds. Otherwise, available data reported in the literature were applied to tentatively identify the compounds. The quantification was performed using a manual integration using baseline to valley integration mode with baseline projection performed (Xcalibur ${ }^{\circledR}$ program, Thermo Finnigan). The following calibration curves were used for quantification: (+)-catechin $\left(y=84950 x-23200, R^{2}=1\right.$; 
LOD $=0.17 \mu \mathrm{g} \mathrm{mL} \mathrm{m}^{-1} ; \mathrm{LOQ}=0.68 \mu \mathrm{g} \mathrm{mL}^{-1}$ ), chlorogenic acid $\left(y=168823 x-161172, R^{2}=0.9999 ; \mathrm{LOD}=0.20 \mu \mathrm{g} \mathrm{mL}^{-1} ; \mathrm{LOQ}=\right.$ $\left.0.68 \mu \mathrm{g} \mathrm{mL} \mathrm{m}^{-1}\right),(-)$-epicatechin $\left(y=10314 x+147331, R^{2}=\right.$ $0.9994 ; \mathrm{LOD}=0.15 \mu \mathrm{g} \mathrm{mL}{ }^{-1} ; \mathrm{LOQ}=0.78 \mu \mathrm{g} \mathrm{mL} \mathrm{m}^{-1}$ ), ferulic acid $\left(y=633126 x-185462, R^{2}=0.9990 ;\right.$ LOD $=0.20 \mu \mathrm{g} \mathrm{mL}^{-1}$; $\left.1.01 \mu \mathrm{g} \mathrm{mL}{ }^{-1}\right)$, naringenin $\left(y=18433 x+78903, R^{2}=0.9998\right.$; $\left.\mathrm{LOD}=0.20 \mu \mathrm{g} \mathrm{mL} \mathrm{m}^{-1} ; \mathrm{LOQ}=0.64 \mu \mathrm{g} \mathrm{mL}^{-1}\right)$, and protocatechuic acid $\left(y=214168 x+27102, R^{2}=0.9999 ;\right.$ LOD $=0.14 \mu \mathrm{g} \mathrm{mL}^{-1}$;

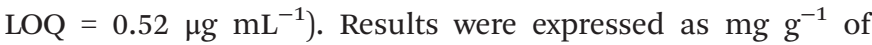
extract.

\subsection{Production of the TPS/PBAT films added with Araucaria angustifolia (Bertol.) Kuntze extract}

The formulations were chosen based on the studies of Olivato et $a .^{23}$ and Olivato et $a .^{14}$ with minor modifications. Glycerol (280 g), citric acid (0.6 g), Araucaria angustifolia (Bertol.) Kuntze extract (CF - control formulation without the extract; P5 - $10 \mathrm{~g}$ of extract; P75 - $15 \mathrm{~g}$ of extract), PBAT (600 g), and starch $(1120 \mathrm{~g})$ were manually mixed in this order, and then processed using a laboratory single-screw extruder (model EL-25, BGM, Brazil) with a screw diameter $(D)$ of $25 \mathrm{~mm}$ and length of $28 D$. The barrel temperature profile was $90 / 120 / 120 /$ $120{ }^{\circ} \mathrm{C}$ from the feeding (zone 1) to die zone (zone 4). The screw speed was $35 \mathrm{rpm}$, and a die with six holes of $2 \mathrm{~mm}$ diameter was used. The obtained extruded cylindrical profiles were pelletized, and the pellets were extruded again to produce the films with a barrel temperature profile of 90/120/125/ $125{ }^{\circ} \mathrm{C}$ in each zone, and $130{ }^{\circ} \mathrm{C}$ for the $50 \mathrm{~mm}$ film-blowing die with internal air to form the film "bubble". The screw speed of $35 \mathrm{rpm}$ was maintained in this stage.

\subsection{Film characterization}

A scanning electron microscope (FEI model Quanta 200, Tokyo, Japan) was used to observe the fractured surface of the films. Samples were previously submerged in liquid nitrogen and then broken (cryogenic fracture). Samples were then stored at $25{ }^{\circ} \mathrm{C}$ in a desiccator with $\mathrm{CaCl}_{2}(\approx 0 \% \mathrm{RH})$ for 3 days and then gold coated (Sputter Coater BAL-TEC SCD 050) before analysis. Images were taken of the fragile fracture (800× magnification) and the film surface (800× magnification).

To analyze color, parameters $L^{*}, a^{*}$, and $b^{*}$ were evaluated using a MiniScan EZ apparatus (HunterLab) at ten points randomly chosen on the film surface. The color difference $\left(\Delta E^{*}\right)$ between samples containing Araucaria angustifolia (Bertol.) Kuntze extract and the control (CF) was calculated using eqn (1), where $\Delta L^{*}, \Delta a^{*}$, and $\Delta b^{*}$ are the differences between the film containing the extract and the control film. ${ }^{24}$

$$
\Delta E^{*}=\sqrt[2]{\left(\Delta L^{*}\right)^{2}+\left(\Delta a^{*}\right)^{2}+\left(\Delta b^{*}\right)^{2}}
$$

The apparent opacity of the films was determined according to the method reported by Park \& $\mathrm{Zhao}^{25}$ with minor modifications using a UV-Vis spectrophotometer (Ocean Optics USB650UV). Samples were cut into rectangles and the thickness was determined with a digital micrometer (Pantec, Brazil) with $0.001 \mathrm{~mm}$ resolution at ten random points. After that, films were stuck to the inner wall of a quartz cuvette $(10 \mathrm{~mm}$ optical path). The samples were then analyzed at an absorbance of $600 \mathrm{~nm}$ (an empty cuvette was used as a reference). Results were presented as the ratio between the absorbance and the film thickness (Abs $600 \mathrm{~nm} \mathrm{~mm}^{-1}$ ).

A texture analyzer, model TA.TX2 plus (Stable Micro Systems, Surrey-England) with a $50 \mathrm{~kg}$ load cell, was used to determine the tensile properties of the films. The tensile tests were based on the ASTM standard D882-91. ${ }^{26}$ For that, ten samples of each formulation $(50 \mathrm{~mm}$ length and $20 \mathrm{~mm}$ width to fit to the tensile grips) were cut in the longitudinal direction. To determine the mechanical properties, the crosshead speed was set at $0.8 \mathrm{~mm} \mathrm{~s}^{-1}$, considering an initial distance between the grips of $30 \mathrm{~mm}$. Before testing, the samples were conditioned at $23 \pm 2{ }^{\circ} \mathrm{C}$ and relative humidity of $53 \pm 2 \%$ for $48 \mathrm{~h}$. The tensile strength (MPa), Young's modulus (MPa) and elongation at break (\%) were determined.

The produced films were analyzed by Differential Scanning Calorimetry (DSC, PerkinElmer, 4000). For that, film samples (previously kept in a desiccator with silica for 1 week) were weighed $(10 \mathrm{mg})$ in aluminum pans and heated from 0 to $300{ }^{\circ} \mathrm{C}$ at $20{ }^{\circ} \mathrm{C} \mathrm{min}^{-1}$ under nitrogen flow (50 $\mathrm{mL} \mathrm{min}{ }^{-1}$ ). Thermogravimetric analysis (TGA) (TG 209-F3, Netzsch) was performed using a sample of approximately $10 \mathrm{mg}$ weighed in an alumina crucible and heated from $20^{\circ} \mathrm{C}$ to $710^{\circ} \mathrm{C}$ at $10^{\circ} \mathrm{C}$ $\min ^{-1}$ under nitrogen flux $\left(20 \mathrm{~mL} \mathrm{~min}{ }^{-1}\right)$.

Films were analyzed for their solubility in water, moisture and water vapor permeability according to the methodology described by Pizzoli et $a .^{27}$ with minor modifications. To determine the moisture content $(M)$, sample sheets were weighed $\left(w_{1}\right)$, conditioning them in a circulation air oven for $24 \mathrm{~h}$ at $70{ }^{\circ} \mathrm{C}$. After this, the sheets were weighed again $(w)$ and the moisture (\%) was calculated using eqn (2).

$$
\% M=\frac{\left(w_{1}-w_{2}\right)}{w_{1}} \times 100
$$

To determine the water solubility (\% SOL), sheet samples $(2 \times 2 \mathrm{~cm})$ were weighed $\left(w_{2}\right)$ and then immersed in water (200 mL, $25 \pm 2{ }^{\circ} \mathrm{C}$ ) for $24 \mathrm{~h}$. Subsequently, the sheet was removed and dried at $70{ }^{\circ} \mathrm{C}$ in a forced air oven for $24 \mathrm{~h}$. Samples were then weighed $\left(w_{3}\right)$ and water solubility (\%) was calculated using eqn (3).

$$
\% \mathrm{SOL}=\frac{\left(w_{2}-w_{3}\right)}{w_{2}} \times 100
$$

The water vapor permeability was determined using appropriate aluminum diffusion cells under a relative humidity $(\mathrm{RH})$ of $2 \%$ inside the cell and $75 \%$ outside the cell. ${ }^{28}$ All tests were carried out in triplicate. The contact angle of the films with water (polar solvent) and diiodomethane (non-polar solvent) was determined by deposition of one drop of the solvent on the film surface (10 measurements were carried out for each determination) followed by image analysis with a goniometer (Ramé-Hart, Inc., Mountain Lakes, NJ, USA). 
The antioxidant activity of the films was measured by the DPPH method after an extraction procedure as described by De Freitas et $a .^{3}$ using ethanol:water mixtures (80:20 and $60: 40 \mathrm{v} / \mathrm{v}$ ) as the solvent. $20 \mathrm{~mL}$ of each mixture were added to the film sample ( $1 \mathrm{~g}$ ), and homogenized using an Ultra-Turrax at $12000 \mathrm{rpm}$ for $10 \mathrm{~min}$, followed by centrifugation at $6000 \mathrm{rpm}$ for $15 \mathrm{~min}$. The supernatant solution was filtered using a syringe filter $(0.45 \mu \mathrm{m})$. For the DPPH assay, the procedure described by Mensor et al. ${ }^{29}$ was used with minor modifications. First, $2.5 \mathrm{~mL}$ of the film extract were mixed with $1 \mathrm{~mL}$ of $0.3 \mathrm{mM}$ DPPH methanol solution (or pure methanol as the control) in a test tube, keeping it in the dark for $30 \mathrm{~min}$. Finally, the absorbance was determined at $518 \mathrm{~nm}$. All samples were analyzed in triplicate. The antioxidant capacity was calculated using a Trolox standard curve $(y=$ $\left.0.0905 x-0.8656 ; R^{2}=0.9984\right)$ and the results were expressed as $\mu \mathrm{mol}_{\mathrm{TE}}$ per $100 \mathrm{~g}_{\text {film. }}$.

\subsection{Statistical analysis}

The obtained results were evaluated using analysis of variance (ANOVA), and the means were compared using Tukey's test at $5 \%$ of significance $(p<0.05)$ using the software Statistica 7.0 (Statsoft, USA).

\section{Results and discussion}

The phenolic profile of the Araucaria angustifolia (Bertol.) Kuntze extract obtained by HPLC-DAD-ESI/MSn is presented in Table 1. A phenolic profile registered at $280 \mathrm{~nm}$ is exemplified in Fig. 1.

The compounds were identified based on their retention time, UV-Vis and mass spectra characteristics. Eight compounds were identified including three phenolic acids (protocatechuic acid, ferulic acid hexoside, and 3,5-O-dicaffeoylqui-

Table 1 Retention time $\left(R_{t}\right)$, wavelengths of maximum absorption in the visible region $\left(\lambda_{\max }\right)$, mass spectral data, tentative identification, and quantification ( $\mathrm{mg} \mathrm{g}^{-1}$ of extract) of the phenolic compounds present in the Araucaria angustifolia (Bertol.) Kuntze extract

\begin{tabular}{|c|c|c|c|c|c|c|}
\hline Peak & $\begin{array}{l}R_{\mathrm{t}} \\
(\min )\end{array}$ & $\lambda_{\max }(\mathrm{nm})$ & $\begin{array}{l}\text { Molecular ion } \\
{[\mathbf{M}-\mathbf{H}]^{-}(\mathrm{m} / \mathrm{z})}\end{array}$ & $\operatorname{MS}^{2}(m / z)$ & Tentative identification & $\begin{array}{l}\text { Quantification } \\
\text { (mg g }{ }^{-1} \text { extract) }\end{array}$ \\
\hline 1 & 4.19 & 274 & 191 & $173(45), 111(100)$ & Quinic $\operatorname{acid}^{(\mathrm{A})}$ & $1.33 \pm 0.04$ \\
\hline 2 & 5.44 & 260.294 & 153 & $109(100)$ & Protocatechuic acid $^{(\mathrm{B})}$ & $1.29 \pm 0.01$ \\
\hline 4 & 7.04 & 280 & 289 & 245 (100), 203 (15), 187 (26), $161(22), 137(5)$ & $(+)$-Catechin ${ }^{(\mathrm{D})}$ & $2.38 \pm 0.04$ \\
\hline 5 & 7.56 & 280 & 577 & 451 (25), 425 (100), 289 (15), 287 (5) & B-type (epi)catechin dimer ${ }^{(\mathrm{D})}$ & $0.91 \pm 0.01$ \\
\hline 6 & 9.66 & 279 & 289 & $245(100), 203(15), 187(26), 161(22), 137(5)$ & (-)-Epicatechin ${ }^{(\mathrm{E})}$ & $1.70 \pm 0.02$ \\
\hline \multicolumn{6}{|c|}{ Total phenolic compounds } & $8.25 \pm 0.05$ \\
\hline
\end{tabular}

Standard calibration curves: A - chlorogenic acid $\left(y=168823 x-161172, R^{2}=0.9999\right) ; \mathrm{B}-$ protocatechuic acid $\left(y=214168 x+27102, R^{2}=\right.$ 0.9999); C - ferulic acid $\left(y=633126 x-185462, R^{2}=0.9990\right) ; \mathrm{D}-(+)$-catechin $\left(y=84950 x-23200, R^{2}=1\right)$; $\mathrm{E}-(-)$-epicatechin $(y=10314 x+$ $\left.147331, R^{2}=0.9994\right) ; \mathrm{F}$ - naringenin $\left(y=18433 x+78903, R^{2}=0.9998\right)$. tr - traces (compounds below LOD amounts).

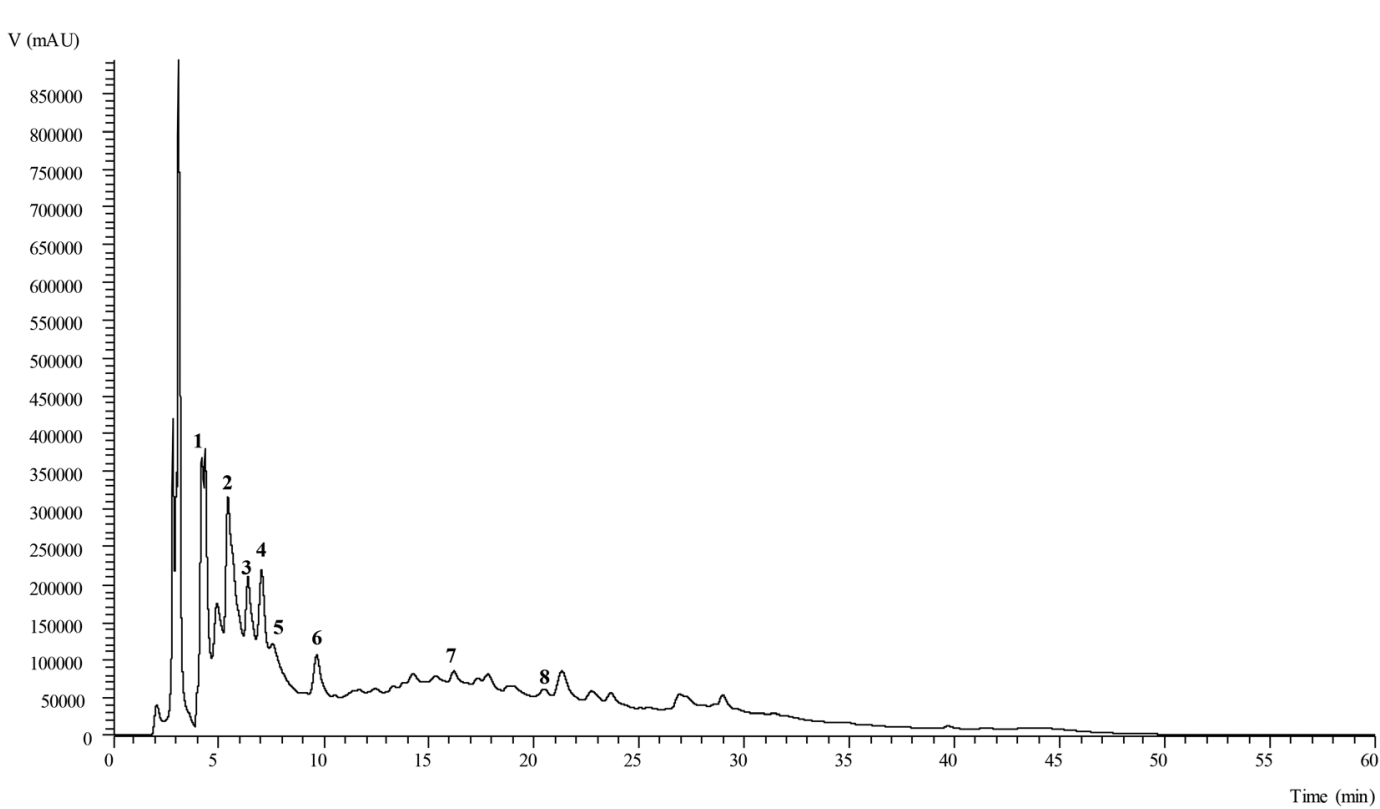

Fig. 1 Phenolic profile of Araucaria angustifolia (Bertol.) Kuntze recorded at $280 \mathrm{~nm}$. 
nic acid), four flavonoid glycoside derivatives, of which three were flavan-3-ols $((+)$-catechin and (-)-epicatechin and B-type (epi)-catechin dimer) and one flavanone (eriodictyol-O-hexoside), and one organic acid (quinic acid). All compounds were previously identified in Araucaria angustifolia (Bertol.) Kuntze shells and cooking water. ${ }^{3}$

$(+)$-Catechin was the compound found at the highest concentration followed by (-)-epicatechin and quinic acid. This latter compound was also identified in the ethanolic extract (95\% v/v) of Araucaria cunninghami leaves and branches by Chen et al. ${ }^{30}$ Protocatechuic acid was the fourth major compound identified, also previously identified in A. Angustifolia extracts by De Freitas et $a l .{ }^{3}$ and Santos et $a l .{ }^{5}$ at the concentrations of $2.06 \mathrm{mg} \mathrm{g}^{-1}$ of extract (Araucaria angustifolia (Bertol.) Kuntze cooking water) and $5.06 \mathrm{mg} \mathrm{g}^{-1}$ of extract (ethanol/water solvent). (-)-Epicatechin derivative compounds were also identified in different amounts by the authors previously cited. In the present work, only eight compounds were identified in the extract of Araucaria angustifolia (Bertol.) Kuntze cooking water, a number of compounds inferior to those identified in the extract used by De Freitas et $a .^{3}$ and Santos et al. ${ }^{5}$ (13 compounds). These differences are possibly related to different sampling periods, locations, climatic differences, and soil. ${ }^{31,32}$

\subsection{Film characterization}

The morphology of CF (control, no extract added), P5 (0.5\% extract), and P75 films (0.75\% extract) was characterized by Scanning Electron Microscopy (SEM). The obtained images of the surface and fractures are shown in Fig. 2.

In the film's surface images, it is possible to observe that the addition of the extract slightly increased film roughness, with a more compact structure for the P75 sample. No change was observed between the microstructure of the control (CF) and the sample with $0.5 \%$ of extract (P5). Similar results were observed for films composed of pomelo peel flours incorpor-
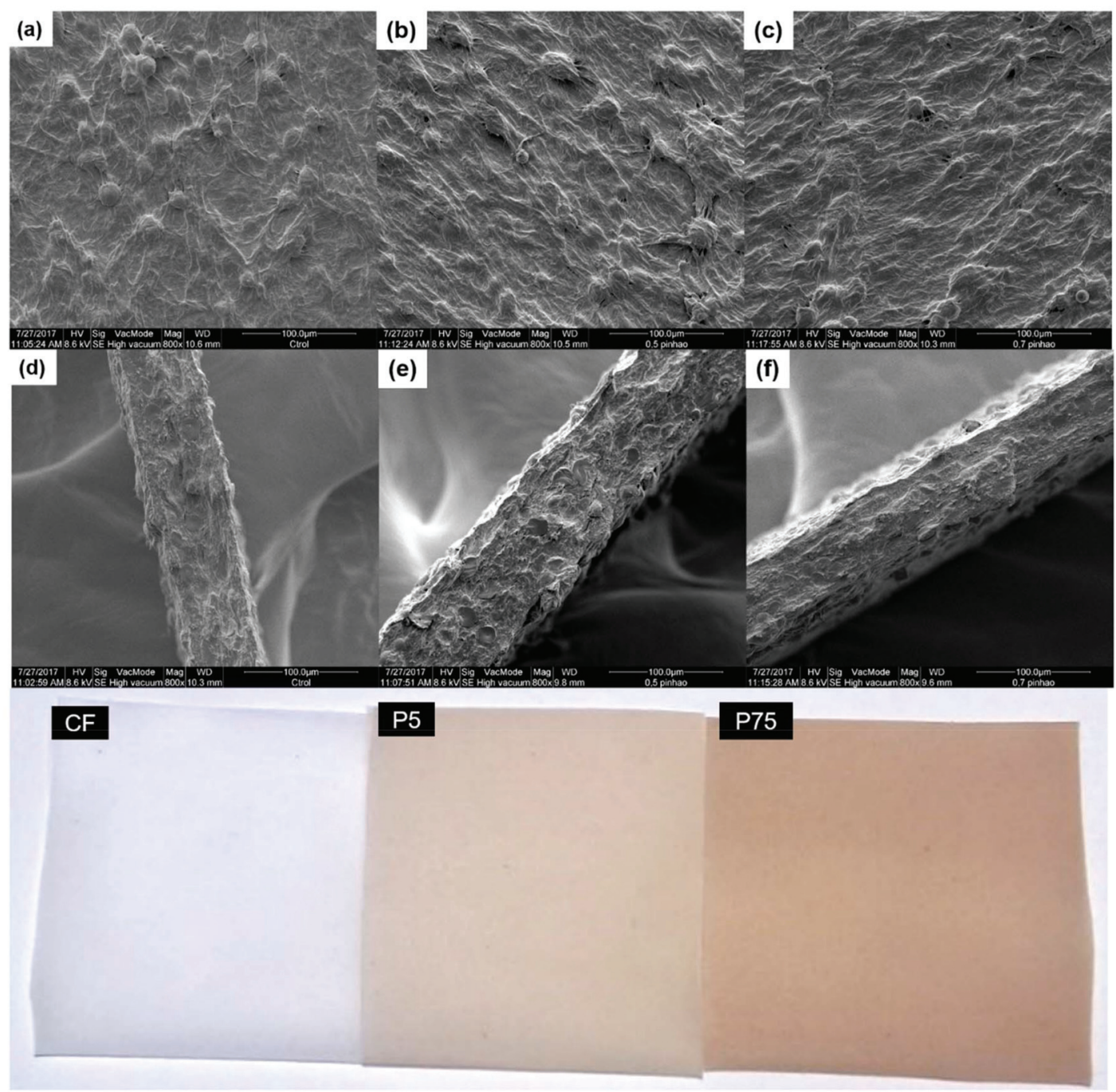

Fig. 2 SEM images of the film surfaces: (a) CF, (b) P5, (c) P75. 800x magnification; SEM images of the films' fragile fracture: (d) CF, (e) P5, (f) P75. 800x magnification; images of the produced films: control (CF), with $0.5 \%$ Araucaria angustifolia (Bertol.) Kuntze extract (P5), and with 0.75\% Araucaria angustifolia (Bertol.) Kuntze extract (P75). 
ated with tea polyphenols, ${ }^{33}$ and wheat gluten films containing gallic and tanic acids. ${ }^{34}$ According to Rattaya, Benjakul, \& Prodpran, ${ }^{35}$ the greater roughness and the compact structures should be due to the bonding intensification between phenolic compounds, and the polymeric matrix via covalent and noncovalent bonds.

The mechanical properties, tensile strength (MPa), Young's modulus (MPa), and elongation at break (\%) of the CF (control, 0\% Araucaria angustifolia (Bertol.) Kuntze extract), P5 (0.5\% Araucaria angustifolia (Bertol.) Kuntze extract), and P75 films (0.75\% Araucaria angustifolia (Bertol.) Kuntze extract) are shown in Table 2.

For both films incorporating Araucaria angustifolia (Bertol.) Kuntze extract, similar characteristics were obtained, which were also comparable to those of the control formulation $(p>$ 0.05). The only exception was found for the elongation at break regarding the sample containing $0.75 \%$ of extract, which differed from the other samples $(p<0.05)$. This behavior could be explained by the more compact microstructure as observed in the SEM images. These results indicate that a more flexible film was obtained with the addition of $0.75 \%$ of Araucaria angustifolia (Bertol.) Kuntze extract. Another point to be emphasized is that the films did not demonstrate significant fragility, which makes them feasible for an actual application. $^{14}$

Table 2 presents the results obtained for the color evaluation and film opacity and Fig. 2 presents the images of the produced films. There was a significant difference $(p<0.05)$ between the control film and the films containing the extract. There was a significant decrease in luminosity $\left(L^{*}\right)$ and $a^{*}$ caused by the addition of the extract, which refers to the color tonality that varies from green (negative values) to red (positive values). On the other hand, there was a significant increase for the $b^{*}$ parameter, which represents the variation from blue

Table 2 Properties related to film characterization: CF (control), P5 (0.5\% Araucaria angustifolia (Bertol.) Kuntze extract), and P75 (0.75\% Araucaria angustifolia (Bertol.) Kuntze extract)

\begin{tabular}{llll}
\hline & \multicolumn{2}{l}{ Mechanical properties } \\
\cline { 2 - 4 } Film formulation & Tensile strength (MPa) & Elongation at break (\%) & Young's modulus (MPa) \\
\hline CF & $5.27^{\mathrm{a}} \pm 0.69$ & $198.15^{\mathrm{a}} \pm 41.30$ & $35.27^{\mathrm{a}} \pm 5.76$ \\
P5 & $5.44^{\mathrm{a}} \pm 0.27$ & $205.15^{\mathrm{a}} \pm 31.96$ & $35.79^{\mathrm{a}} \pm 3.10$ \\
P75 & $5.50^{\mathrm{a}} \pm 0.43$ & $280.18^{\mathrm{b}} \pm 80.40$ & $35.93^{\mathrm{a}} \pm 3.10$ \\
\end{tabular}

\begin{tabular}{|c|c|c|c|c|c|}
\hline Film formulation & \multicolumn{5}{|c|}{ Color and opacity } \\
\hline $\mathrm{CF}$ & $94.84^{\mathrm{b}} \pm 0.13$ & $5.51^{\mathrm{b}} \pm 0.05$ & $8.27^{\mathrm{a}} \pm 0.46$ & - & $25.00^{\mathrm{a}} \pm 1.48$ \\
\hline P75 & $88.07^{\mathrm{a}} \pm 0.71$ & $2.22^{\mathrm{a}} \pm 0.34$ & $19.82^{\mathrm{b}} \pm 1.00$ & $14.32^{\mathrm{a}} \pm 1.70$ & $39.46^{c} \pm 1.17$ \\
\hline
\end{tabular}

TGA thermal properties

\begin{tabular}{|c|c|c|c|c|c|c|}
\hline \multirow[b]{2}{*}{ Film formulation } & \multirow[b]{2}{*}{$T_{\text {TPS initial }}\left({ }^{\circ} \mathrm{C}\right)$} & \multirow[b]{2}{*}{$T_{\mathrm{TPS} \max }\left({ }^{\circ} \mathrm{C}\right)$} & \multirow[b]{2}{*}{$T_{\text {PBAT initial }}\left({ }^{\circ} \mathrm{C}\right)$} & \multirow[b]{2}{*}{$T_{\text {PBAT max }}\left({ }^{\circ} \mathrm{C}\right)$} & \multicolumn{2}{|c|}{$\begin{array}{l}\text { Weight loss in } \\
\text { degradation (\%) }\end{array}$} \\
\hline & & & & & TPS & PBAT \\
\hline CF & 257.1 & 312.6 & 344.8 & 395.3 & 38.06 & 30.95 \\
\hline P5 & 256.4 & 311.0 & 341.4 & 398.4 & 38.03 & 41.45 \\
\hline P75 & 252.1 & 309.0 & 343.1 & 396.9 & 39.62 & 31.53 \\
\hline
\end{tabular}

\begin{tabular}{|c|c|c|c|c|c|c|}
\hline Film formulation & \multicolumn{6}{|c|}{ DSC thermal properties } \\
\hline P5 & -51 & 114.1 & 2.398 & 58.3 & 0.3760 & 0.33 \\
\hline P75 & -48 & 115.0 & 3.048 & 59.3 & 0.2165 & 0.19 \\
\hline
\end{tabular}

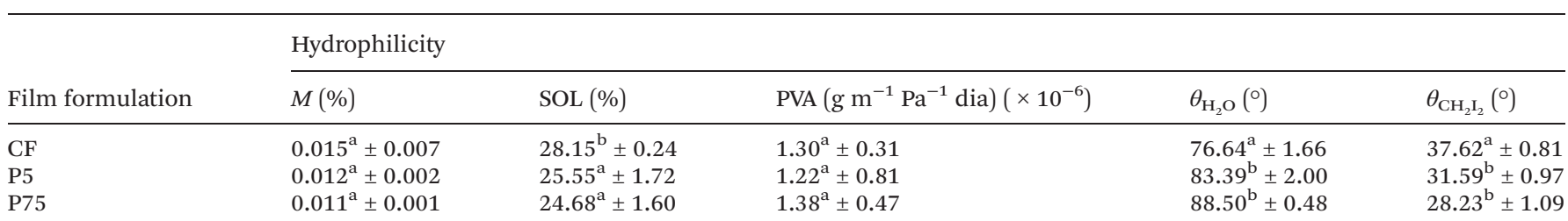

Results expressed as mean \pm standard deviation; a, b, and c different letters in the same column indicate a significant difference between the treatments by Tukey's test $(p<0.05)$. 
(a)
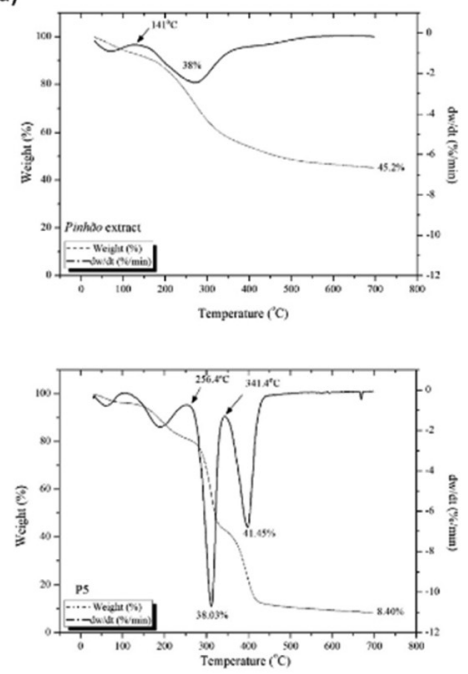
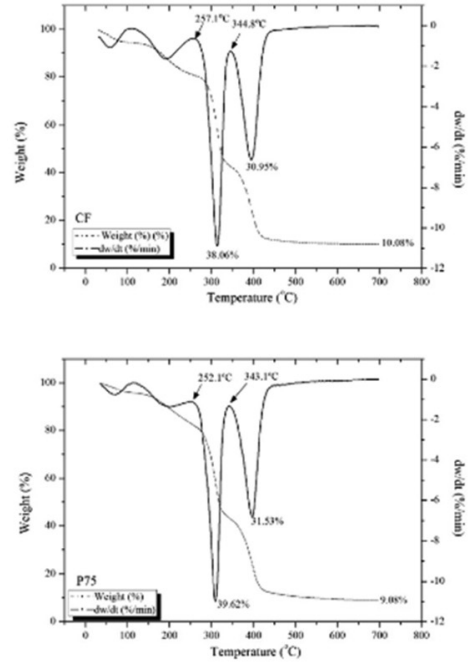

(b)

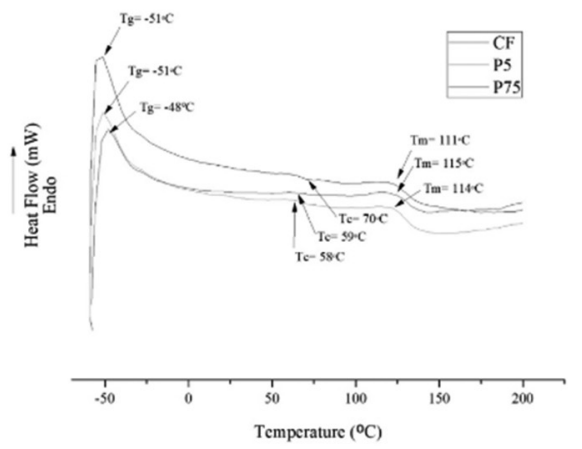

Fig. 3 (a) TGA and DTG curves of Araucaria angustifolia (Bertol.) Kuntze extract and the films: control (CF), with 0.5\% Araucaria angustifolia (Bertol.) Kuntze extract (P5), and with $0.75 \%$ Araucaria angustifolia (Bertol.) Kuntze extract (P75); (b) DSC thermograms obtained for the films: control (CF), with $0.5 \%$ Araucaria angustifolia (Bertol.) Kuntze extract (P5), and with $0.75 \%$ Araucaria angustifolia (Bertol.) Kuntze extract (P75).

(negative values) to yellow (positive values). These differences resulted in a significant $(p<0.05)$ increase in the color variation $\left(\Delta E^{*}\right)$ of films containing the extract when compared to the control (Fig. 2), where the increase in darkness as the extract content increases, characteristic imparted by the Araucaria angustifolia (Bertol.) Kuntze extract color, can be clearly noted. An increase in opacity was also detected, which corroborates the results of color parameters. More opaque films can be advantageous since they are able to protect more effectively food against light, preventing lipid oxidation. ${ }^{36,37}$

Fig. 3 presents the TGA (Thermogravimetric Analysis) and DTG (Differential Thermal Analysis) curves, while Table 2 shows the initial and maximum temperatures of the degradation peaks. Fig. 3 includes the DSC thermograms obtained for the produced films. The incorporation of $7.5 \%$ of Araucaria angustifolia (Bertol.) Kuntze extract influenced the glass transition temperature $\left(T_{\mathrm{g}}\right)$ of starch, as can be seen in the results listed in Table 2.

Film degradation occurs in four stages, with the initial two peaks related to moisture loss and glycerol degradation. The third peak is related to TPS degradation at $\simeq 320{ }^{\circ} \mathrm{C}$ and the fourth peak is associated with the PBAT degradation at $\simeq 400{ }^{\circ} \mathrm{C}^{38}$

It is worth noting that the initial degradation temperature of TPS was higher for CF and P5 samples. However, the weight loss associated with TPS degradation was slightly higher for the P75 sample, thus presenting a slightly lower thermal stability when compared to the control and P5 samples.

These results suggest that the extract of Araucaria angustifolia (Bertol.) Kuntze cooking water presented a greater affinity with TPS and influenced its thermal stability due to its hydrophilic characteristic. Furthermore, it is worth noting that TGA results indicated that all films and the pure extract are thermally stable at temperatures up to $250^{\circ} \mathrm{C}$, which demonstrates that phenolic compounds present in the extract did not degrade during the extrusion process.

$T_{\mathrm{g}}$ was identified at $-51{ }^{\circ} \mathrm{C}$ for $\mathrm{CF}$ and $\mathrm{P} 5$ samples for control and P5 samples; however, the $T_{\mathrm{g}}$ was $-48{ }^{\circ} \mathrm{C}$ for the P75 sample. This displacement in $T_{\mathrm{g}}$ can be related to the interactions between the phenolic compounds from the Araucaria angustifolia (Bertol.) Kuntze extract and TPS, resulting in an increasing constraint to the mobility of starch chains.

Fig. 3 shows the melting temperature $\left(T_{\mathrm{m}}\right)$ related to the butylene terephthalate (BT) rigid segments, with a maximum point at $111{ }^{\circ} \mathrm{C}$ for the CF sample, and at $114{ }^{\circ} \mathrm{C}$ and $115{ }^{\circ} \mathrm{C}$ for P5 and P75 samples, respectively. Also, the peaks related to the crystalline melting temperature $\left(T_{\mathrm{c}}\right)$ from butylene adipate (BA) segments occurred at $70{ }^{\circ} \mathrm{C}, 58{ }^{\circ} \mathrm{C}$, and $59{ }^{\circ} \mathrm{C}$ for the control (CF), P5, and P75 samples, respectively. ${ }^{39}$ The crystallinity degree of the films decreased with the increase of extract concentration, suggesting that it has the ability to limit the crystalline growth of PBAT, as also reported by Olivato et al. ${ }^{40}$ for TPS, PBAT, and sepiolite nanocomposites.

Table 3 shows the results obtained for moisture, solubility, and water vapor permeability analysis. The moisture results presented no significant differences $(p>0.05)$ between the treatments, while the films containing Araucaria angustifolia (Bertol.) Kuntze extract were less soluble in water, differing significantly $(p<0.05)$ from the control formulation. Adilah et $a l .{ }^{36}$ produced films composed of fish protein and soy protein isolate containing mango seed extract and observed that the solubility of the films decreased as the incorporated mango seed extract concentration increased. The authors described that this fact could be associated with interactions between the protein and the phenolic compounds of the extract present in the film matrix, which led to a reduction of available hydroxyls and amino groups interacting with water. 
Table 3 Results obtained for the antioxidant capacity of the films (DPPH) and quantification (mg per $100 \mathrm{~g}_{\text {film }}$ ) of the phenolic compounds as a function of the solvent composition used to recover the phenolic compounds (ethanol: water v/v) from CF (control), P5 (0.5\% Araucaria angustifolia (Bertol.) Kuntze extract), and P75 (0.75\% Araucaria angustifolia (Bertol.) Kuntze extract)

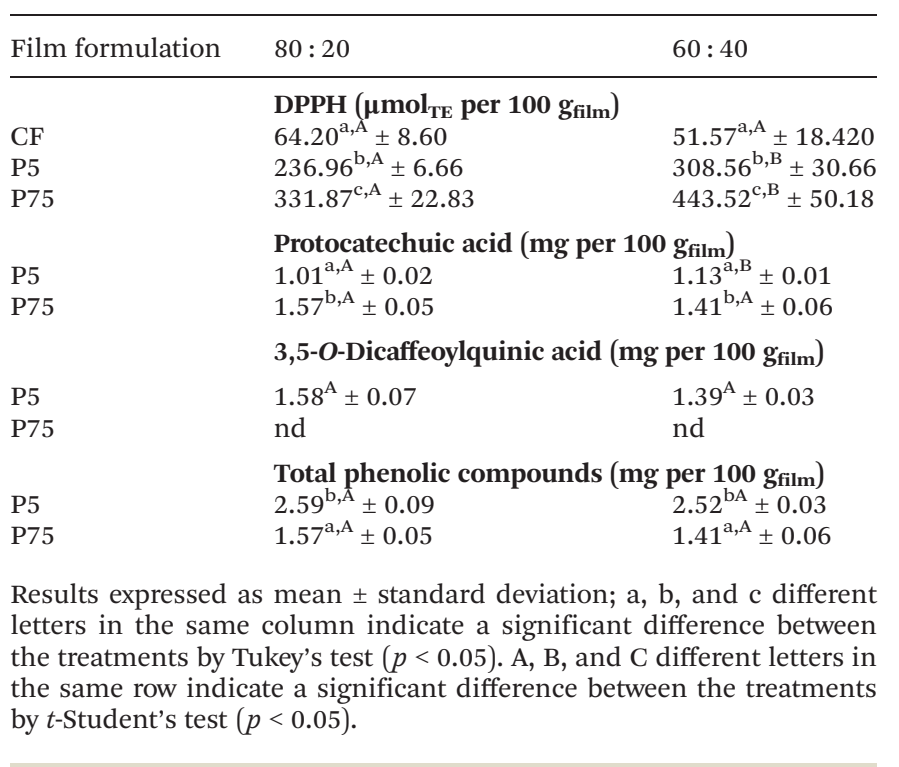

The addition of the Araucaria angustifolia (Bertol.) Kuntze extract did not significantly influence $(p<0.05)$ the water vapor permeability of the films. It is important to note that, even with the decrease in polymeric material crystallinity, there was no significant increase in the measured WVP. Most of the foods are more susceptible to deterioration when exposed to high humidity contents. Therefore, food packaging must ensure a good barrier to water vapor permeability. ${ }^{36,41}$ Water vapor permeability should be as low as possible when the objective of the packing is to reduce moisture transfer between the packaged foodstuff and the atmosphere. ${ }^{42}$ Shirai, Grossmann, Yamashita, Garcia, \& Müller ${ }^{43}$ found higher WVP values when compared to the values obtained in the present work, which are in the range of $5 \times 10^{-6} \mathrm{~g} \mathrm{~s}^{-1} \mathrm{~m}^{-1} \mathrm{~Pa}^{-1}$, for a similar film composition.

The contact angles with water (polar) and diiodomethane (non-polar) were determined aiming to evaluate the hydrophilic or hydrophobic nature of the films (Table 3). It is worth noting that water contact angles superior to $65^{\circ}$ represent surfaces with a hydrophobic character, while smaller angles reflect a hydrophilic character. ${ }^{44}$ The obtained results were significantly different $(p<0.05)$ when comparing the control and the samples containing the extract, the latter showing a decrease in wettability. We also observed a significant decrease $(p<0.05)$ for the contact angle of the films containing Araucaria angustifolia (Bertol.) Kuntze extract with diiodomethane. This behavior also indicates that the hydrophobic characteristic of the films changed due to the presence of the extract, probably due to the interactions between the phenolic compounds from the extract with both material's microstructure and solvent (polar and non-polar).

\subsection{Antioxidant capacity of the films}

Table 3 shows the results for the antioxidant capacity in terms of DPPH, obtained for the films containing Araucaria angustifolia (Bertol.) Kuntze extract. The antioxidant capacity was evaluated as a function of the extraction solvent used to recover the phenolic compound from the polymeric matrices. Different solvent polarities can lead to a selective extraction of these compounds since the phenolic compounds may interact with film's components (TPS, PBAT and glycerol).

It is possible to observe a significant increase $(p<0.05)$ in the antioxidant capacity measured by DPPH, as the Araucaria angustifolia (Bertol.) Kuntze extract concentration increases in the film formulations. Values found were 6 and 9 times fold those for P5 and P75 samples, respectively, when compared to the control formulation (solvent composition $60: 40 \mathrm{v} / \mathrm{v}$ ). In the case of the $80: 20 \mathrm{v} / \mathrm{v}$ solvent composition, the results were 3 and 5 times superior to those for for P5 and P75, respectively, when compared to the control film. A significant difference $(p<0.05)$ was also detected between the DPPH results for the same film matrix as a function of the solvent composition used, apart from the control film formulation.

Regarding the quantification of the phenolic compounds extracted from the polymeric matrix, only two compounds were identified, specifically protocatechuic acid and 3,5-Odicaffeoylquinic acid. Although catechin has been identified as the major compound present in the Araucaria angustifolia (Bertol.) Kuntze extract, it could not be detected in any of the obtained film extracts. This behavior is possibly related to the interaction observed between the phenolic compounds and the polymeric matrix, as previously discussed. Both compounds, protocatechuic acid and 3,5-O-dicaffeoylquinic acid, may present weak interaction with TPS/PBAT films, being released to the extraction solvent.

\section{Conclusion}

The results obtained in the present work indicated the possibility to apply the Araucaria angustifolia (Bertol.) Kuntze extract (considered a byproduct of Araucaria angustifolia (Bertol.) Kuntze cooking process) to the production of TPS/PBAT films by blown extrusion. The obtained phenolic profile of the Araucaria angustifolia (Bertol.) Kuntze extract indicated the presence of eight phenolic compounds, with (+)-catechin and (-)-epicatechin as the most abundant compounds. Films' microstructural and thermal characterization indicated interactions between the phenolic compounds of the extract and polymeric matrix, a fact intensified in the film containing $0.75 \%$ of extract, where both the crystallinity degree and starch glass transition temperature decreased.

Color and opacity of the films were significantly affected $(p<0.05)$ by the presence of the Araucaria angustifolia (Bertol.) Kuntze extract, which provided a brown coloration to the films. There was no significant change $(p>0.05)$ in film water vapor permeation. However, their water solubility was significantly affected by the incorporation of Araucaria angustifolia 
(Bertol.) Kuntze extract. Lower solubility values were found for the films containing Araucaria angustifolia (Bertol.) Kuntze extract and the evaluated contact angles with water and diiodomethane indicated that the presence of phenolic compounds can change the film hydrophilic/hydrophobic nature. Finally, film formulations containing Araucaria angustifolia (Bertol.) Kuntze extract showed significant antioxidant capacity by the DPPH test, indicating the viability to propose these films as active packaging materials.

\section{Conflicts of interest}

There are no conflicts to declare.

\section{Acknowledgements}

The authors thank CNPq (Chamada Universal - MCTI/CNPq no. 14/2014, Processo 447768/2014-0), CAPES (Master's scholarship) and Fundação Araucária (Programa Universal/ Pesquisa Básica e Aplicada 24/2012, protocolo 7334133700514041013 ) for the financial support and they also thank Associate Laboratory LSRE-LCM - UID/EQU/50020/2019 funded by national funds through FCT/MCTES (PIDDAC) and FEDER under Programme PT2020 for financial support to CIMO (UID/AGR/00690/2019) and to the national funding by FCT, P.I., through the institutional scientific employment program-contract for L. Barros contracts. The authors are also grateful to FEDER-Interreg España-Portugal programme for financial support through the project 0377_Iberphenol_6_E.

\section{References}

1 D. Piñeros-Hernandez, C. Medina-jaramillo, A. LópezCórdoba and S. Goyanes, Food Hydrocolloids, 2017, 63, 488495.

2 R. M. Peralta, E. A. Koehnlein, R. F. Oliveira, V. G. Correa, R. C. G. Corrêa, L. Bertonha, A. Bracht and I. C. F. R. Ferreira, Trends Food Sci. Technol., 2016, 54, 85-93.

3 T. B. De Freitas, C. H. K. Santos, M. V. da Silva, M. A. Shirai, M. I. Dias, L. Barros, M. F. Barreiro, I. C. F. R. Ferreira, O. H. Gonçalves and F. V. Leimann, Food Packag. Shelf Life, 2018, 15, 28-34.

4 E. A. Koehnlein, A. E. S. Carvajal, E. M. Koehnlein, J. D. S. Coelho-Moreira, F. D. Inácio, R. Castoldi, A. Bracht and R. M. Peralta, Afr. J. Food Sci., 2012, 6, 512-518.

5 C. H. K. Santos, M. R. Baqueta, A. Coqueiro, M. I. Dias, L. Barros, M. F. Barreiro, I. C. F. R. Ferreira, O. H. Gonçalves, E. Bona, M. V. da Silva and F. V. Leimann, Food Chem., 2018, 261, 216-223.

6 S. M. da Silva, E. A. Koehnlein, A. Bracht, R. Castoldi, G. R. de Morais, M. L. Baesso, R. A. Peralta, C. G. M. de Souza, A. B. de Sá-Nakanishi and R. M. Peralta, Food Res. Int. , 2014, 56, 1-8.
7 R. F. Oliveira, G. A. Gonçalves, F. D. Inácio, E. A. Koehnlein, C. G. M. de Souza, A. Bracht and R. M. Peralta, Nutrients, 2015, 7, 5601-5614.

8 C. S. Branco, T. S. Rodrigues, É. D. Lima and M. Salvador, Cancer Cell Microenviron., 2015, 2, 1-5.

9 C. S. Branco, A. Duong, A. K. Machado, A. Wu, G. Scola, A. C. Andreazza and M. Salvador, Mol. Biol. Rep., 2019, $1-13$.

10 N. Peelman, P. Ragaert, A. Vandemoortele, E. Verguldt, B. De Meulenaer and F. Devlieghere, Innovative Food Sci. Emerging Technol., 2014, 26, 319-329.

11 F. V. Leimann, O. H. Gonçalves, L. S. Sakanaka, A. S. B. Azevedo, M. V. Lima, F. Barreiro and M. A. Shirai, in Handbook of Food Bioengineering Volume 9: Food Packaging and Preservation, ed. A. M. Grumezescu and A. M. Holban, Elsevier, London, United Kingdom, 1st edn, 2018, pp. 87-135.

12 G. Mensitieri, E. Di Maio, G. G. Buonocore, I. Nedi, M. Oliviero, L. Sansone and S. Iannace, Trends Food Sci. Technol., 2011, 22, 72-80.

13 J. Zanela, M. A. Shirai, M. O. Reis, S. Mali, M. V. E. Grossmann and F. Yamashita, Starch/Staerke, 2015, 67, 1011-1019.

14 J. B. Olivato, M. V. E. Grossmann, F. Yamashita, M. M. Nobrega, M. R. S. Scapin, D. Eiras and L. A. Pessan, Int. J. Food Sci. Technol., 2011, 46, 1934-1939.

15 P. G. Seligra, L. E. Moura, L. Famá, J. I. Druzian and S. Goyanes, Polym. Int., 2016, 65, 938-945.

16 R. P. H. Brandelero, F. Yamashita and M. V. E. Grossmann, Carbohydr. Polym., 2010, 82, 1102-1109.

17 Y. Fourati, Q. Tarrés, P. Mutjé and S. Bou, Carbohydr. Polym., 2018, 199, 51-57.

18 M. A. B. S. Nunes, V. A. D. Marinho, G. A. M. Falcão, E. L. Canedo, M. A. G. Bardi and L. H. Carvalho, Polym. Test., 2018, 70, 281-288.

19 M. O. Reis, J. B. Olivato, J. Zanela, F. Yamashita, M. Victoria and E. Grossmann, Polimeros, 2017, 27, 129-135.

20 D. Wei, H. Wang, Z. Ziaee, F. Chibante, A. Zheg and H. Xiao, Mater. Sci. Eng., C, 2016, 58, 986-991.

21 P. S. Garcia, M. V. E. Grossmann, M. A. Shirai, M. M. Lazaretti, F. Yamashita, C. M. O. Muller and S. Mali, Ind. Crops Prod., 2014, 52, 305-312.

22 S. M. F. Bessada, J. C. M. Barreira, L. Barros, I. C. F. R. Ferreira and M. B. P. P. Oliveira, Ind. Crops Prod., 2016, 89, 45-51.

23 J. B. Olivato, M. V. E. Grossmann, A. P. Bilck and F. Yamashita, Carbohydr. Polym., 2012, 90, 159-164.

24 L. F. Wang and J. W. Rhim, Int. J. Biol. Macromol., 2015, 80, 460-468.

25 S. Il Park and Y. Zhao, J. Agric. Food Chem., 2004, 52, 19331939.

26 ASTM, in Annual book of ASTM, American Society for Testing and Materials, Philadelphia, PA, 2001.

27 A. P. D. O. Pizzoli, N. G. Marchiore, S. J. De Souza, P. D. De Freitas Santos, O. H. Gonçalves, F. Yamashita, L. Bracht, M. A. Shirai and F. V. Leimann, J. Appl. Polym. Sci., 2016, 43039. 
28 ASTM, in Annual book of ASTM, American Society for Testing and Materials, Philadelphia, PA, 2000.

29 L. L. Mensor, F. S. Menezes, G. G. Leitão, A. S. Reis, T. C. dos Santos, C. S. Coube and S. G. Leitão, Phytother. Res., 2001, 15, 127-130.

30 J. Chen, M. L. Yang, J. Zeng and K. Gao, Phytochem. Lett., 2013, 6, 41-45.

31 L. Nchabeleng, J. Med. Plants Res., 2012, 6, 1662-1666.

32 M. Yahyaoui, J. Bouajila, S. Cazaux and M. Abderrabba, Phytomedicine, 2018, 41, 13-23.

33 H. Wu, Y. Lei, R. Zhu, M. Zhao, J. Lu, D. Xiao, C. Jiao, Z. Zhang, G. Shen and S. Li, Food Hydrocolloids, 2019, 90, 41-49.

34 A. Hager, K. J. R. Vallons and E. K. Arendt, J. Agric. Food Chem., 2012, 60, 6157-6163.

35 S. Rattaya, S. Benjakul and T. Prodpran, J. Food Eng., 2009, 95, 151-157.

36 A. N. Adilah, B. Jamilah and Z. A. N. Hanani, Food Hydrocolloids, 2018, 74, 207-218.
37 C. M. Bitencourt, C. S. Fávaro-Trindade, P. J. A. Sobral and R. A. Carvalho, Food Hydrocolloids, 2014, 40, 145-152.

38 L. Lendvai, A. Apostolov and J. Karger-Kocsis, Carbohydr. Polym., 2017, 173, 566-572.

39 P. G. Seligra, C. M. Jaramillo, L. Famá and S. Goyanes, Carbohydr. Polym., 2016, 138, 66-74.

40 J. B. Olivato, J. Marini, F. Yamashita, E. Pollet, M. V. E. Grossmann and L. Avérous, Mater. Sci. Eng., C, 2017, 70, 296-302.

41 A. N. Adilah, B. Jamilah, M. A. Noranizan and Z. A. N. Hanani, Food Packag. Shelf Life, 2018, 16, $1-7$.

42 N. Gontard, S. Guilbert and J. Cuq, J. Food Sci., 1992, 57, 190-195.

43 M. A. Shirai, M. V. E. Grossmann, F. Yamashita, P. S. Garcia and C. M. O. Müller, Carbohydr. Polym., 2013, 92, 19-22.

44 L. J. P. Córdoba and P. J. A. Sobral, J. Food Eng., 2017, 213, 47-53. 